\title{
Diagnóstico por Teledermatologia em paciente do Alto Rio Solimões: um caso de escabiose crostosa
}

\author{
Diagnosis by Teledermatology of a patient from the Alto Solimões River: a case of Crusted Scabies
}

\section{Diagnóstico por Teledermatología en paciente del Alto Río Solimões: un caso de Escabiosis Costrosa}

\author{
Anderson da Paz Penha. Universidade Federal do Amazonas (UFAM). anderson.paz@gmail.com (Autor correspondente) \\ Gisele Teixeira Milano. Universidade Federal do Amazonas (UFAM). gtmilano@yahoo.com.br \\ Thiago Paiva Guimarães. Universidade Federal do Amazonas (UFAM). thiagopguimaraes@gmail.com \\ Ricardo César Garcia Amaral Filho. Universidade do Estado do Amazonas (UEA). amaral.mfc@gmail.com \\ Rossilene Conceição da Silva Cruz. Fundação Alfredo da Matta (FUAM). rossilenecruz@uol.com.br
}

\section{Resumo}

A Teledermatologia estuda 0 uso das tecnologias de telecomunicação e informática na assistência dermatológica sem a atuação presencial do especialista. Neste trabalho, é relatado o processo diagnóstico de um caso de escabiose crostosa (sarna norueguesa) em paciente idoso da região do Alto Rio Solimões, por meio de recursos de Teledermatologia. Além disso, os autores discutem os avanços dessa tecnologia que possibilita a assistência a distância para comunidades ribeirinhas e indígenas, sobretudo em áreas isoladas da Amazônia Legal, nas quais inúmeras doenças são negligenciadas e subdiagnosticadas.

\section{Abstract}

Teledermatology uses telecommunication technology and informatics on dermatologic practice without the presence of a specialist. This paper describes the diagnostic process of a Crusted Scabies (Norwegian Scabies) case in an elderly patient from the Alto Solimões River region using teledermatology resources. Moreover, the authors discuss the progress of these technologies, which allow healthcare assistance for those living in remote indigenous and riverine communities, particularly in isolated areas of the Legal Amazon where many diseases are neglected or underdiagnosed.

\section{Resumen}

La Teledermatología usa las tecnologías de las telecomunicaciones y de la informática para dar asistencia dermatológica sin la presencia de un especialista. Este artículo describe el proceso de diagnóstico de un caso de escabiosis costrosa (sarna norueguesa) en un paciente anciano de la región del Alto Rio Solimões, a través de recursos de la Teledermatología. Además, los autores discuten los avances de estas tecnologías que permiten llevar asistencia médica a las comunidades costeras e indígenas remotas, especialmente a aquellas de zonas aisladas del Legal Amazon, en las cuales numerosas enfermedades son negligenciadas y subdiagnosticadas.

Palavras-chave:

Telemedicina

Dermatologia

Saúde da População Rural

Escabiose

Sarcoptes scabiei

Keywords:

Telemedicine

Dermatology

Rural Health

Scabies

Sarcoptes scabiei

\section{Palabras clave:}

Telemedicina

Dermatología

Salud Rural

Escabiosis

Sarcoptes scabiei 


\section{Introdução}

A Teledermatologia estuda o uso das tecnologias de telecomunicação e informática na assistência dermatológica sem a atuação presencial do especialista, com potencial de levar atenção à saúde, educação e segunda opinião às populaçóes com dificuldades de acesso para açóes presenciais ${ }^{1}$.

No Brasil, a expansão do Programa Telessaúde, criado pelo Ministério da Saúde em 2007, possibilitou a oferta de assistência a distância para comunidades ribeirinhas e indígenas, sobretudo em áreas isoladas da Amazônia Legal, nas quais inúmeras doenças são negligenciadas e subdiagnosticadas ${ }^{2,3}$.

O presente artigo descreve o processo diagnóstico de um caso clínico de escabiose crostosa (sarna norueguesa) por meio de recursos de Teledermatologia, em paciente idoso no município de Tabatinga, na região do Alto Rio Solimóes.

O caso foi identificado em janeiro de 2011, durante as atividades do Internato Rural do Curso de Medicina de uma universidade pública, com suporte do Serviço de Telemedicina do Hospital de Guarnição de Tabatinga - Exército Brasileiro (HGuT/EB).

Quanto aos aspectos éticos, foram seguidas as prerrogativas da Resolução N. 196/96 do Conselho Nacional de Saúde (CNS/MS), a partir da obtenção do termo de consentimento livre e esclarecido, assinado por um responsável legal, a fim de garantir a preservação da identidade do paciente em questâo.

\section{Detalhamento do caso}

Paciente idoso, 81 anos, masculino, não pensionista, natural de Lima-Peru, residente no município de Tabatinga, estado do Amazonas, foi identificado por meio de visita domiciliar junto à equipe da Unidade Básica de Saúde Santa Rosa (Semsa) no dia 27 de janeiro de 2011. Possuía antecedentes patológicos de hipertensáo arterial em controle irregular e paraplegia, como sequela de acidente vascular cerebral ocorrido 7 anos antes, sendo dependente funcional dos cuidadores e com mobilidade restrita ao domicílio.

Há 2 anos apresentava lesôes cutâneas iniciadas com pápulas eritemato-pruriginosas difusas nos pés, evoluindo com acometimento de membros superiores e inferiores, além de tórax, abdome e dorso. As lesóes tornaram-se ressecadas e com descamação intensa.

Foi levado a diversas consultas no HGuT, porém sem tratamento resolutivo, recebendo diagnóstico inicial de dermatite seborreica. Na época, o município não dispunha de médicos especialistas em Dermatologia.

Em outubro de 2010, foi hospitalizado na enfermaria de Clínica Médica do HGuT, com diagnóstico de pneumonia comunitária, desidrataçẫo e dermatose a esclarecer.

Em visita domiciliar no dia 27 de janeiro de 2011, foi realizado exame físico com o qual puderam ser constatadas as condiçôes inadequadas de higiene do paciente e da residência. Ele apresentava eritema difuso e infiltraçóes cutâneas, lesóes crostosas e descamativas, de aspecto liquenificado e hiperceratótico, em toda regiáo extensora e flexora de membros superiores e inferiores, região palmar bilateral, nos pés, tórax, abdome e dorso (Figura 1a, b). As lesóes poupavam somente a face, couro cabeludo e genitália. Também apresentava acentuada onicólise e distrofia ungueal em pododáctilos, além de pequenas úlceras de decúbito em regiâo lombossacra (Figura 2a, b).

A cuidadora (filha) informou que outros familiares apresentavam lesões papulares difusas em membros inferiores, com prurido noturno, porém sem descamação. $\mathrm{Na}$ ocasião da visita, foram solicitados exames laboratoriais preliminares e feito o registro fotográfico das alteraçóes cutâneas.

O caso foi enviado para o Ambulatório Virtual, para avaliação assíncrona pelos consultores especialistas da Teledermatologia (PTA/UEA), por meio da plataforma digital IPTV ${ }^{\circledR}$. Em seguida, foi realizada teleconferência para maior elucidação das informaçôes fornecidas, sendo aventada a hipótese diagnóstica de escabiose crostosa. O plano terapêutico proposto incluía estratégia tópica (com loção de Permetrina a 5\%) e sistêmica (com 2 comprimidos de Ivermectina $6 \mathrm{mg}$ em dose única, com repetição da dose no $8^{\circ}$ dia, e, caso necessário, mais duas doses no $16^{\circ}$ e $24^{\circ}$ dia subsequentes). O esquema também incluía loção ceratolítica com ácido salicílico e anti-histamínico sedativo por via oral. 

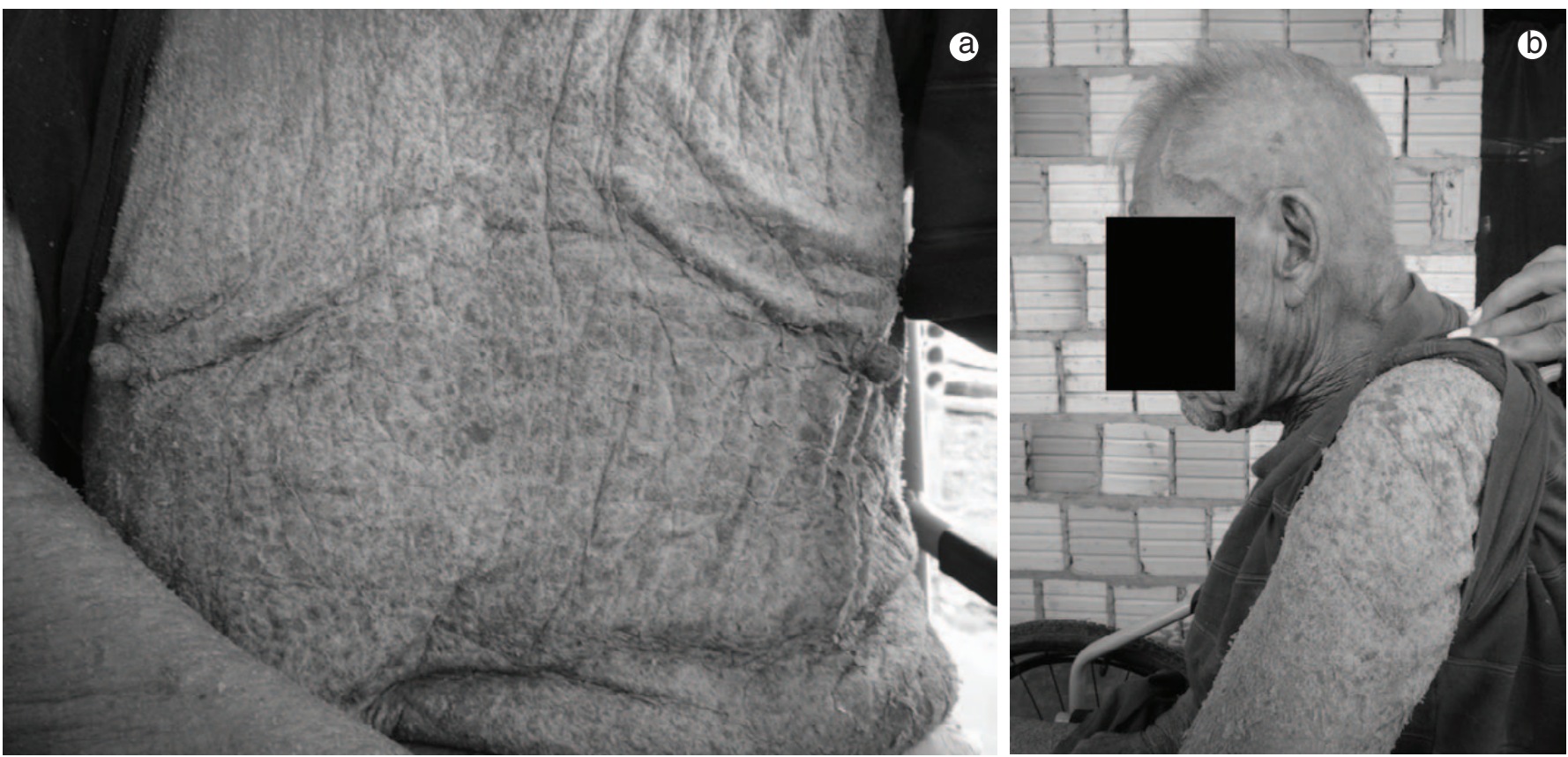

Figura 1. a) Lesões crostosas, hiperceratóticas e descamativas, com inúmeras fissuras em região peitoral e abdome; b) A extensão das lesões poupando face, pescoço e escalpo.
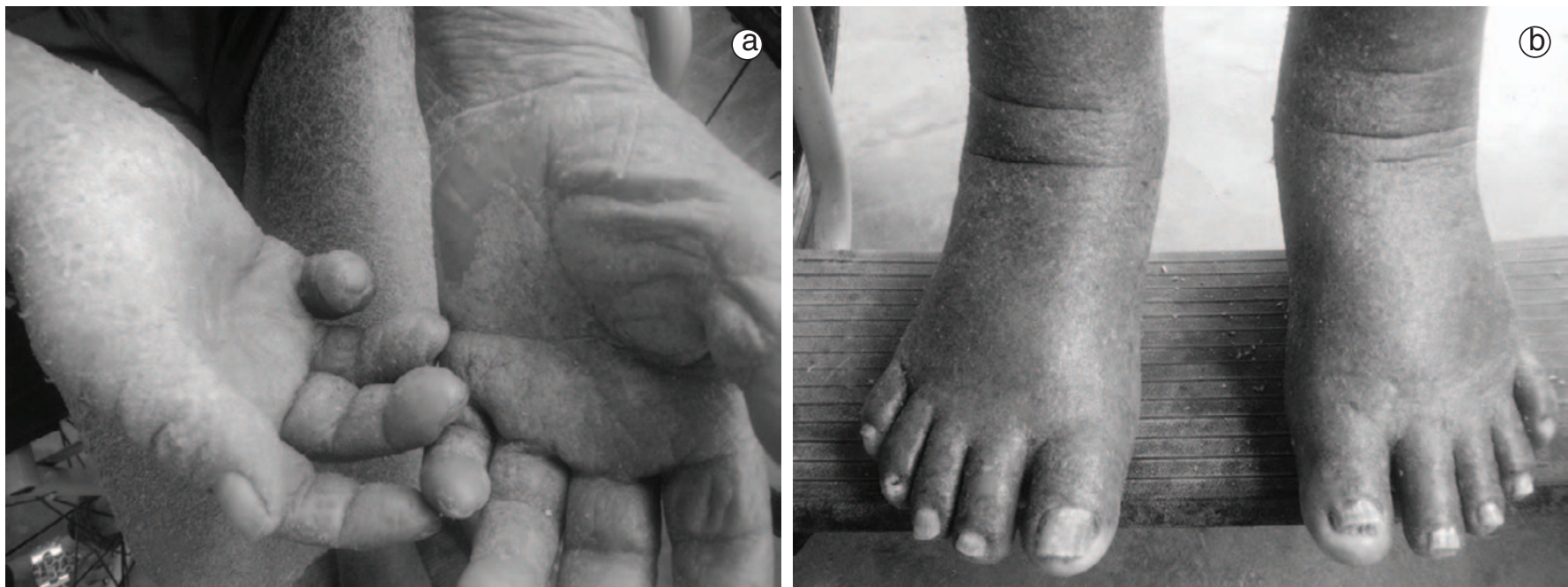

Figura 2. a) Lesões crostosas e hiperceratóticas presentes em região palmar bilateralmente; b) Onicólise acentuada e onicodistrofia.

Com apoio do Laboratório de Fronteira de Tabatinga (Lafron), foram adquiridos materiais para escarificação cutânea e fixação em lâmina com KOH 10\% para microscopia direta das lesôes. Entretanto, o paciente foi a óbito no dia 8 de fevereiro de 2011, na ocasião da visita domiciliar subsequente para orientação terapêutica, coleta de amostra cutânea e entrega de medicamentos. A causa mortis foi definida na declaração de óbito como insuficiência respiratória pela perícia médica da Polícia Civil de Tabatinga.

Quanto aos exames laboratoriais, foi possível obter somente o resultado post mortem do hemograma realizado e velocidade de hemossedimentação, com os seguintes resultados: (a) Eritrograma: eritrócitos 3,7 milhôes (4,6 \pm 0,7); hematócrito 32,0\% $(41,0 \pm 6,0)$; hemoglobina 9,9 g/dL (13,5 $\pm 2,5)$; VCM 86 fl (89 \pm 9); (b) Leucograma: leucócitos 8.500 (3.600-11.000); bastôes 1\% (0-3\%); segmentados 33\% (45-75\%); eosinófilos 55\% (0-7\%); linfócitos 08\% (20-50\%); monócitos 03\% (2-10\%); (c) VHS $40 \mathrm{~mm} 1^{\text {a }}$ hora (até $\left.8 \mathrm{~mm}\right)$. 
Após o episódio, os nove familiares (adultos e crianças) foram tratados com doses habituais de Ivermectina, apresentando resposta satisfatória e cura da dermatozoonose, o que foi confirmado através de nova visita domiciliar, ocorrida em julho de 2011, cerca de cinco meses após o episódio.

\section{Discussão}

Os autores trazem neste relato a discussão de dois temas relevantes para a prática diária do Médico de Família e Comunidade: a raridade dos casos de escabiose crostosa e as facilidades da Telemedicina.

A escabiose é causada por ácaros que são ectoparasitas da espécie Sarcoptes scabiei variação hominis ${ }^{4}$. As manifestaçôes clássicas incluem prurido intenso e generalizado, com piora no período noturno. Qualquer área do corpo pode ser acometida por pápulas pruriginosas e inflamatórias, usualmente poupando face e escalpo. O diagnóstico baseia-se na história clínica e exame físico, além da história familiar e dos contactantes ${ }^{4,5}$.

A forma difusa, também conhecida como escabiose crostosa ou sarna norueguesa, é uma rara complicação, quando há superinfestação pelo artrópode com grande número de parasitas na pele, ultrapassando até dois milhôes de exemplares, sendo um estágio altamente contagioso da doença ${ }^{4}$.

A progressão da forma primária para a difusa é incomum, e a suscetibilidade para doença severa está relacionada a uma série de condiçôes predisponentes ${ }^{4-6}$. Ocorre em indivíduos imunocomprometidos (HIV/Aids, transplantados, neoplasias, em uso crônico de corticoides e imunossupressores, doenças autoimunes), pacientes institucionalizados (creches, asilos, presídios, hospitais psiquiátricos) e aqueles com debilidade física ou cognitiva (idosos acamados e dependentes, síndrome de Down $)^{7-10}$. Há relatos na literatura descrevendo casos em comunidades indígenas e quilombolas ${ }^{4-6}$.

As lesôes iniciam de forma pouco definida, com pápulas eritematosas que rapidamente tendem à generalização. As placas coalescem e se tornam de aspecto hiperceratótico, psoriasiforme e descamativo 5 .

Podem acometer mãos e pés, com envolvimento de unhas e leito subungueal, onde há frequentemente onicodistrofia e onicomicose associada ${ }^{4,5}$. Odor fétido, crostas em proeminências ósseas e fissuras também podem aparecer. Em idosos, tais fissuras favorecem infecçóes bacterianas secundárias e aumentam o risco de sepse ${ }^{11}$. Nessa fase, o prurido é incipiente ou mesmo ausente, presumivelmente por neuropatia sensorial secundária a infestação $0^{5,11}$.

O diagnóstico laboratorial de sarna norueguesa é simples, através de escarificação cutânea com microscopia direta em $\mathrm{KOH} 10 \%$ ou dermatoscopia ${ }^{5,8}$. Porém, é necessário que a suspeita clínica seja aventada. Infelizmente, a escabiose crostosa é erroneamente notificada, por não especialistas, como reação adversa a medicamentos, dermatite seborreica, psoríase, lúpus eritematoso sistêmico, ictiose ou pênfigo bolhoso ${ }^{5,8,9}$. Médicos de família e clínicos gerais devem estar atentos para as possíveis manifestaçóes atípicas da escabiose, incluindo casos que envolvam cabeça e pescoço ${ }^{4,9}$.

O tratamento deve ser tópico, com aplicação de loção de Permetrina 5\%, por 7 dias consecutivos, e após duas vezes por semana até a cura. $\mathrm{O}$ uso de sabonetes ceratolíticos pode ser combinado à terapia tópica. Deve-se iniciar tratamento sistêmico com Ivermectina oral $\left(200 \mu \mathrm{g} / \mathrm{kg} /\right.$ dose única), dado no $1^{\circ}, 2^{\circ}, 8^{\circ}, 9^{\circ}$ e $15^{\circ}$ dias. Nos pacientes com infestação severa, pode-se estender o curso da medicação oral, com doses adicionais nos dias 22 e 29 do esquema $a^{4,5}$.

No caso relatado pelos autores, as lesóes poupavam face e couro cabeludo. O leucograma mostrou eosinofilia acentuada, o que chama atenção para um perfil de resposta imunológica humoral diferenciada do hospedeiro. Altos níveis de IgE total e eosinofilia periférica já foram descritos em outros estudos ${ }^{12}$.

Ademais, não foi possível iniciar o plano terapêutico e acompanhar a evolução do quadro do paciente. O diagnóstico clínico foi apoiado a partir do componente visual registrado na visita domiciliar, e após teleconsultoria ${ }^{2}$ de especialistas em Dermatologia, vinculados ao PTA/UEA. Além disso, houve cura do surto familiar com uso de Ivermectina, o que reforça presuntivamente a hipótese de escabiose crostosa.

A Dermatologia foi uma das especialidades que mais avançaram na Telemedicina, devido à natureza visual do exame dermatológico. Dois tipos de mecanismo são empregados nessa área: store-and-forward (armazenamento e envio) e real-time (tempo real). Esses sistemas podem ser distinguidos no que diz respeito à sincronia, ou seja, na forma pela qual a transmissão e a recepção são feitas ${ }^{13,14}$. Embora evidências indiquem que a acurácia diagnóstica da consulta presencial seja 5 a $19 \%$ superior à da Teledermatologia, inúmeros fatores influenciam a resolutividade dos casos e na satisfação do paciente, como o difícil acesso ao serviço de dermatologia e os custos do atendimento ${ }^{13,14}$. 
Além da barreira geográfica, existem diversas deficiências (humanas, materiais, tecnológicas) para a efetiva implementação das açôes de Telemedicina. O município de Tabatinga está localizado na Tríplice Fronteira com Peru e Colômbia, a 1.607 km por via fluvial de Manaus. O deslocamento fluvial entre as cidades dura cerca de 7 dias, o que dificulta o acesso da população rural aos serviços especializados ${ }^{15}$.

Atualmente, os casos de média e alta complexidade são encaminhados para a capital através de protocolo de tratamento fora do domicílio (TFD) ou de consultas especializadas agendadas pelo Sistema de Regulação da Secretaria de Estado de Saúde do Amazonas (SISREG/SUSAM).

Diante do exposto, os autores ressaltam a importância de ferramentas de Telemedicina, no apoio diagnóstico de doenças de difícil controle e suporte às equipes de saúde da família em regióes rurais ou geograficamente isoladas, onde a presença de médicos especialistas é escassa e onde há baixa fixação desses profissionais, como a Região Amazônica ${ }^{1,2,13,15}$.

\section{Agradecimentos}

Os autores agradecem o suporte recebido das seguintes instituiçôes: (a) Departamento de Saúde Coletiva da Faculdade de Medicina da Universidade Federal do Amazonas; (b) Pólo de Telemedicina da Amazônia - Universidade do Estado do Amazonas; (c) Secretaria Municipal de Saúde de Tabatinga/AM; (d) Serviço de Telemedicina do Hospital de Guarnição de Tabatinga/Exército Brasileiro.

\section{Referências}

1. Miot HA, Paixão MP, Lung WC. Teledermatologia: passado, presente e futuro. An Bras Dermatol. 2005;80(5):523-32. http://dx.doi.org/10.1590/ S0365-05962005000600011

2. Brasil. Ministério da Saúde. Portaria n².546, de 27 de outubro de 2011. Redefine e amplia o Programa Telessaúde Brasil, que passa a ser denominado Programa Nacional Telessaúde Brasil Redes (Telessaúde Brasil Redes). Diário Oficial da República Federativa do Brasil, Brasília; 2011. Seção 1, n. 208, p. 50-51.

3. Silva CS, Souza MB, Duque IA, Medeiros LM, Melo NR, Araújo CA, et al. Teledermatologia: correlação diagnóstica em serviço primário de saúde. An Bras Dermatol. 2009; 84(5): 489-93. http://dx.doi.org/10.1590/S0365-05962009000500007

4. Chosidow O. Clinical Practice: Scabies. N Engl J Med 2006; 354: 1718-27. http://dx.doi.org/10.1056/NEJMcp052784

5. Goldstein BG, Goldstein AO. Scabies. [acesso em 2012 Fev]. Disponível em: http://www.uptodate.com/contents/scabies?source=search_result\&s earch $=$ Scabies\&selectedTitle $=1 \sim 49$

6. Rayes AA, Mohamed lagi, B. Crusted (Norwegian) scabies in an HIV infected man: a case report. Libyan J Infect Dis. 2007; 1(1): 54-55.

7. Pierezan CC, Vettorato G, Schwartz J, Gervini RL. Escabiose verrucosa em paciente transplantado renal. An Bras Dermatol. 2000 jan.-fev.; 75(1): 31 -34.

8. Towersey L, Cunha MX, Feldman CA, Castro CG, Berger TG. Dermoscopy of Norwegian scabies in a patient with acquired immunodeficiency syndrome. An Bras Dermatol. 2010; 85(2): 221-3. http://dx.doi.org/10.1590/S0365-05962010000200013

9. Subramaniam G, Kaliaperumal K, Duraipandian J, Rengasamy G. Norwegian scabies in a malnourished young adult: a case report. $J$ Infect Dev Ctries 2010; 4(5): 349-351.

10. Vignesh R, Shankar EM, Devaleenal B, Pachamuthu B, Thousen SM, Sekar R, et al. Atypically distributed cutaneous lesions of Norwegian scabies in an HIV-positive man in South India: a case report. J Med Case Rep. 2008; 2:82. http://dx.doi.org/10.1186/1752-1947-2-82

11. Wong SS, Woo PC, Yuen KY. Unusual laboratory findings in a case of Norwegian scabies provided a clue to diagnosis. J Clin Microbiol. 2005 May; 43(5): 2542-4. http://dx.doi.org/10.1128/JCM.43.5.2542-2544.2005

12. Walton SF. The immunology of susceptibility and resistance to scabies. Parasite Immunol. 2010 Aug; 32(8): 532-40. http://dx.doi.org.br/10.1111/ j.1365-3024.2010.01218.x

13. Soirefmann M, Boza JC, Comparin C, Cestarini TF, Wen CL. Cybertutor: um objeto de ensino na Dermatologia. An Bras Dermatol. $2010 ; 85(3): 400-2$. http://dx.doi.org/10.1590/S0365-05962010000300021

14. Warshaw EM, Greer N, Hillman Y, Hagel E, MacDonald R, Rutks I, Wilt TJ. Teledermatology for Diagnosis and Management of Skin Conditions: A Systematic Review of the Evidence [Internet]. Washington: Department of Veterans Affairs (US); 2010 Jan.

15. Superintendência da Zona Franca de Manaus - Suframa. [página na internet]. ALC's - Tabatinga. Acesso [21 Abril 2012]. Disponível em: http://www. suframa.gov.br/suframa_descentralizadas_alcs_tabatinga.cfm. 